\section{Should the Pharmacy Profession Lead the Medication Reconciliation Process?}

\section{THE "PRO" SIDE}

Pharmacists and pharmacy technicians are absolutely the best health care professionals to perform medication reconciliation.

The most challenging part of medication reconciliation is obtaining the best possible medication history (BPMH). Pharmacists have always received formal training at the undergraduate level in obtaining medication histories, and this training is now being offered in pharmacy technician programs. Studies have shown that BPMHs obtained by pharmacists are more accurate and more comprehensive than histories obtained by other health care professionals. ${ }^{1,2}$ There is also a growing body of literature supporting the utilization of trained pharmacy technicians in obtaining medication histories. ${ }^{3-5}$ Extensive training of nursing staff would be required before members of this profession would be able to obtain comparable BPMHs. Also, in a teaching hospital there is a constant turnover of medical trainees who are unfamiliar with institutional documentation practices; as such, it makes more sense for this responsibility to remain with a small group of permanent staff members.

Pharmacists and pharmacy technicians have a more indepth knowledge of drugs than other health care professionals. Their knowledge of both brand and generic names and the various formulations and strengths or concentrations of drugs is of value in obtaining the BPMH. Furthermore, their knowledge of the hospital formulary and the availability of drugs both in hospital and in the community aids in identifying medicationrelated issues as the patient moves through the continuum of care. $^{6-8}$

As part of seamless pharmaceutical care, hospital pharmacists and pharmacy technicians have relationships with their community pharmacy counterparts and have knowledge of their practices. They are familiar with medication-related processes in the community and can communicate directly with community practitioners by telephone or fax. As such, they can efficiently and effectively obtain information from and provide information to community pharmacies.

Prompt identification and documentation of previously unidentified discrepancies during medication reconciliation by pharmacists and pharmacy technicians lead to timely intervention and avoidance of adverse events. Medication reconciliation has been shown to reduce adverse drug reactions and events, reduce the use of health services, and improve quality of life, patient satisfaction, and medication adherence. Most importantly, admission drug histories obtained as part of a clinical pharmacy service have been associated with reduced mortality rates. ${ }^{9,10}$
While any hospital admission is stressful for the patient and his or her family, the role and expertise of pharmacists and pharmacy technicians is clear: we focus on drug therapy, and we can therefore be more efficient and effective in informationgathering and intervention. Within a multidisciplinary team, however, specific roles must be designated to ensure completion of certain tasks, to prevent inefficiencies, and to avoid duplication of effort.

Pharmacists and pharmacy technicians are uniquely qualified to ensure that medication regimens are properly identified and documented throughout the hospital stay and to ensure review of medications at transitions of care. They have the knowledge and skills to lead and optimize this service for patients.

\section{References}

1. Reeder TA, Mutnick A. Pharmacist- versus physician-obtained medication histories. Am J Health Syst Pharm 2008;65(9):857-860.

2. Nester TM, Hale LS. Effectiveness of a pharmacist-acquired medication history in promoting patient safety. Am J Health Syst Pharm 2002; 59(22):2221-2225.

3. Remtulla S, Brown G, Frighetto L. Best possible medication history by a pharmacy technician at a tertiary care hospital. Can J Hosp Pharm 2009; 62(5):402-405.

4. Michels RD, Meisel SB. Program using pharmacy technicians to obtain medication histories. Am J Health Syst Pharm 2003;60(19):1982-1986.

5. Johnston R, Saulnier L, Gould O. Best possible medication hisotry in the emergency department: comparing pharmacy technicians and pharmacists. Can J Hosp Pharm 2010;63(5):359-365.

6. MacKinnon NJ. Evidence in action, acting on evidence. Adopting medication reconciliation and seamless care services. Ottawa $(\mathrm{ON})$ : Canadian Institutes of Health Research; 2006 [cited 2011 May 26]. Available from: www.cihr-irsc.gc.ca/e/30676.html

7. Tam VC, Knowles SR, Cornish PL, Fine N, Marchesano R, Etchells EE. Frequency, type and clinical importance of medication history errors at admission to hospital: a systematic review. CMAJ 2005;173(5):510-515.

8. Cornish PL, Knowles SR, Marchesano R, Tam V, Shadowitz S, Juurlink $\mathrm{DN}$, et al. Unintended medication discrepancies at the time of hospital admission. Arch Intern Med 2005;165(4):424-429.

9. Kaboli PJ, Hoth AB, McClimon BJ, Schnipper JL. Clinical pharmacists and inpatient medical care. A systematic review. Arch Intern Med 2006; 166(9):955-964

10. Bond CA, Raehl CL. Clinical pharmacy services, pharmacy staffing, and hospital mortality rates. Pharmacotherapy 2007;27(4):481-493.

Elaine Wong, BScPhm

Medication Safety/Critical Care Pharmacist

Pharmacy Department

Children's Hospital of Eastern Ontario

Ottawa, Ontario 


\section{THE "CON" SIDE}

Medication reconciliation is recognized as a proven intervention to prevent adverse drug events. ${ }^{1}$ Why then do we continue to struggle with its implementation? Why are physicians, nurses, pharmacists, and pharmacy technicians continuing to debate our collective responsibilities in this process? And why do we continue trying to designate one profession as the lead?

As is the case for many complex problems, the answers to these questions lie in certain collective behaviours: we know why this issue is important, and most of us know what to do about it, but we often don't act on this knowledge. In other words, there continues to be a gap between what we know and what we do. This phenomenon is not unusual in a process of change or quality improvement. ${ }^{2}$

Health care organizations across the country have been trying to implement medication reconciliation over the past several years. Many organizations formally embarked upon this process as participants in the Safer Healthcare Now! initiative, which involved process improvement teams under pharmacy leadership. In fact, when this proven intervention was adopted as a Required Organizational Practice (ROP) by Accreditation Canada, it resided in the Medication Management standards. Both of these initiatives reinforced the perception that the process of medication reconciliation should be led by pharmacy. Yet anyone who has been actively involved in this process would have to agree that it is simply too complex to be the sole responsibility of any one discipline, be it pharmacy, nursing, or medicine. In fact, as time has elapsed, and as our efforts to implement medication reconciliation have continued, the wisdom of the aphorism "It takes a village ..." has taken on immense meaning in the context of this important process. It has become very clear that successful systems of medication reconciliation develop and incorporate cooperation and collaboration among multiple health care professionals. In fact, one could argue that the transition of the medication reconciliation ROP to the program- or service-specific standards of Accreditation Canada occurred in response to the fact that medication reconciliation is a multidisciplinary process for which the program or service is ultimately responsible.

The Canadian Society of Hospital Pharmacists (CSHP), in its position statement on the role of the pharmacist in medication reconciliation, ${ }^{3}$ identified this process as a shared responsibility of the patient, physicians, nurses, and pharmacy staff. It is best accomplished through the collaborative efforts of the interdisciplinary team to develop a model tailored to the practice environment, the resources available, and the needs of the individual patient. ${ }^{3}$ The fact that the CSHP has seen fit to develop a position statement on this important process is a testament to the leadership that hospital pharmacy has demonstrated thus far. However, despite wide acceptance of medication reconciliation as a shared responsibility, it is telling that the Canadian Medical Association, the Canadian Nurses Association, and the Canadian Association of Pharmacy Technicians have not developed similar statements. It is important that these key groups undertake their own discipline-specific discussions to affirm their respective commitments to the medication recon- ciliation process. Even more powerful would be a joint position statement: What could be a better affirmation of our collective commitment to the prevention of adverse drug events?

In today's challenging and fast-paced health care environment, all care providers are being called upon to optimize limited resources and to eliminate duplication of effort and steps that lack value from our care processes. In this context, the overall role of the pharmacist actually represents a mix of 5 key roles and responsibilities: provision of direct patient care; drug use management; management of the drug distribution system; education of patients and their families, other health care professionals, and the pharmacists of the future; and participation in research. ${ }^{4}$ Furthermore, there is continuing evidence that clinical pharmacists and the services they provide for patients are having a growing effect on health care outcomes. ${ }^{5,6}$ For example, 7 interventions performed by pharmacists have been determined to have positive effects on mortality: participating on cardiopulmonary resuscitation teams, providing in-service education, managing adverse drug reactions, providing drug information, participating in medical rounds, managing drug protocols, and obtaining drug histories on admission. ${ }^{7}$ It has been recommended that these services be considered a core set of clinical pharmacy services that should be universally provided by pharmacists. Given the evidence supporting the positive effects of this range of interventions, it stands to reason that pharmacy cannot and should not be exclusively dedicated to the medication reconciliation process. Likewise, our physician, nurse, and pharmacy technician partners in the medication reconciliation process could cite similar discipline-specific interventions that are core to their respective scopes of practice and that should be priorities in their delivery of care.

Many teams are now using the concept of positive deviance to overcome the challenges encountered in successfully implementing the process of medication. Positive deviance "is an approach to behavioral and social change based on the observation that in any community, there are people whose uncommon but successful behaviors or strategies enable them to find better solutions to a problem than their peers, despite facing similar challenges and having no extra resources or knowledge

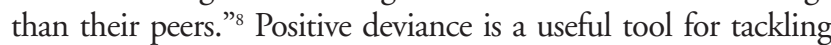
complex problems that are deeply rooted in behaviour. It is a bottom-up strategy to effect change by the people closest to the challenge (see http://positivedeviance.ca/). Using this bottom-up strategy, the health care team identifies how the process is best implemented in their specific area of care.

At the end of the day, there are 2 important facts to consider:

- Medication reconciliation is here to stay: it is a proven intervention to reduce adverse drug events, and it is an ROP of Accreditation Canada.

- Medication reconciliation requires a multidisciplinary approach. To be successful, it must be performed by different professionals at different transition points. ${ }^{1}$

What is the way forward from here? The time has come to end the debate on who should lead this process. Rather, we must "just do it", as the ad tells us. The path forward should include, at a minimum, the following elements:

- Professional associations for physicians, nurses, and pharmacy technicians should join the CSHP in developing a position 
statement on the role of these professions in the medication reconciliation process. This is essential in order for each discipline to "own" its part in this intervention.

- Patient care teams should take a critical look at their processes, using the positive deviance tool, to determine the optimal models and methods for performing medication reconciliation in their respective care environments. This will not be a one-size-fits-all solution.

Medication reconciliation is an important process for improving medication safety. In the spirit of continuous quality improvement, which is integral to every important process, research should continue, with the objective of improving medication reconciliation processes and comparing different models. In the meantime, let's support one another and work together to get it done for the benefit of our patients. It really does not need to be any more complicated than this.

\section{References}

1. Getting started kit: medication reconciliation prevention of adverse drug events: how-to guide. Canadian Patient Safety Institute; 2007 May [cited $2011 \mathrm{Apr}$ 15]. Available from: www.saferhealthcarenow.ca/EN/Interventions/medrec/ Documents/Acute\%20Care/Med\%20Rec\%20(Acute\%20Care)\% 20Getting\%20Started\%20Kit.pdf

2. The breakthrough series: IHI's collaborative model for achieving breakthrough improvement [IHI Innovation Series white paper]. Boston (MA): Institute for Healthcare Improvement; 2003.
3. Medication reconciliation: statement on the role of the pharmacist. Ottawa (ON): Canadian Society of Hospital Pharmacists; 2009. Available from: www.cshp.ca/dms/dmsView/1_S_Med_Rec_2009.pdf

4. Hospital pharmacists: information paper on direct patient care and beyond. Ottawa (ON): Canadian Society of Hospital Pharmacists; 2010.

5. Kaboli PJ, Hoth AB, McClimon BJ, Schnipper JL. Clinical pharmacists and inpatient medical care: a systematic review. Arch Intern Med 2006; 166(9):955-964.

6. Makowsky MJ, Koshman SL, Midodzi WK, Tsuyuki RT. Capturing outcomes of clinical activities performed by a rounding pharmacist practicing in a team environment: the COLLABORATE study. Med Care 2009; 47(6):642-650

7. Bond CA, Raehl CL. Clinical pharmacy services, pharmacy staffing, and hospital mortality rates. Pharmacotherapy 2007;27(4):481-493.

8. Positive deviance. In: Wikipedia, the free encyclopedia. [Modified 2011 Aug 15; cited 2011 Sep 14]. Available from: http://en.wikipedia.org/wiki/ Positive_Deviance

9. Gardam M, Gitterman L. A new approach to MedRec: SHN MedRec teleconference [audio recording; slide presentation]. Safer Healthcare Now! 2011 Jan 19 [cited 2011 Sep 14]. Available from: www.saferhealthcarenow.ca/ EN/events/NationalCalls/2011/Pages/National\%20Call\%20-\%20 Med\%20Rec\%20-\%20January\%2019,\%202011.aspx

Moira Wilson, BScPharm

Director of Pharmacy

Horizon Health Network

New Brunswick

\begin{tabular}{|c|c|c|}
\hline & Ad Page & Prescribing Information \\
\hline Eli Lilly / Insulin & 307 & 379,380 \\
\hline Hospira / Docetaxel & 308 & - \\
\hline Hospira / Precedex & 312,313 & 381,382 \\
\hline Pfizer / Fragmin & 304 & $375-378$ \\
\hline Pharmaceutical Partners of Canada / Corporate & IFC & - \\
\hline Pharmaceutical Partners of Canada / Corporate & $\mathrm{OBC}$ & - \\
\hline Sandoz / Corporate & 302 & - \\
\hline Sandoz / Corporate & IBC & - \\
\hline
\end{tabular}

